\title{
Unravelling the epidemiology of late-onset and asymptomatic carriers of FAP ATTR V30M in a Portuguese population
}

\author{
Carolina Lemos $^{1 *}$, Teresa Coelho ${ }^{2}$, Miguel Alves-Ferreira ${ }^{1}$, Diana Santos ${ }^{1}$, Jorge Sequeiros ${ }^{1}$, Alda Sousa $^{1}$ \\ From First European Congress on Hereditary ATTR amyloidosis \\ Paris, France. 2-3 November 2015
}

\section{Background}

Familial Amyloid Polyneuropathy (FAP ATTRV30M) is an AD systemic amyloidosis, due to a point mutation in the transthyretin (TTR) gene. Although in Portugal the disease has been characterized by its early onset (lower than 40yrs), a wider age-at-onset (AO) variability has been uncovered. The mean AO is 35.3 , but more and more late-onset (higher than $50 \mathrm{yrs}$ ) cases are being ascertained, often matched with older asymptomatic parents. Our aim now was to look into late-onset cases and agedasymptomatic carriers in order to unravel familial aggregation of late-onset and to characterize these families regarding their epidemiology.

\section{Methods}

From the largest registry worldwide with 2754 patients (678 families), we analyzed a group of 326 late-onset cases (133 families) regarding gender and also their transmitting parent. Additionally we analyzed 222 asymptomatic carriers on regular follow-up, aged above 40 at last observation and their first-degree relatives, belonging to 122 families. We performed a descriptive analysis and used the Student's t-test for comparisons between groups.

\section{Results}

Age-at-onset was 60.03 for men and 59.25 for women (NS), as opposed to the general sample where women had a later onset (37.6) than men (33.4). Familial aggregation of late-onset cases is apparent, with some families having up to 11 late-onset cases. Out of 678 probands, $40 \%$ had no affected parent at time of diagnosis, this figure being
$86 \%(115 / 133)$ among late-onset probands. These parents had died with no signs of the disease mostly at old-age. No one had an affected parent with early-onset of the disease.

For asymptomatic carriers, age-at-last-observation varies between 40 and 49 for 103 subjects and was above 50 for 119 of them. Mean age-at-last-observation was 54.06 (SD: 12.2; range: 40-89) and no gender differences were found. We were able to identify 92 transmitting-parents (59 fathers, 33 mothers) with know AO. Their mean AO was 56.91 (SD: 12.8; range: 25-80) and no differences in $\mathrm{AO}$ were found between parent's gender. Also, we found a mean $\mathrm{AO}$ close to 40 years for siblings of these asymptomatic carriers (mean: 39.91; SD: 8.89; range: 24-65).

\section{Conclusions}

While most of FAP probands had one affected parent (as expected in an AD disease), a significant number has a late-onset and no affected parent at time of diagnosis. We confirmed familial aggregation of late-onset cases. We also found that for late-onset cases no gender differences are observed. This shows that some families are protected from the severe manifestations of FAP. Due to these different clinical aspects of FAP in late-onset patients it is crucial to explore mechanisms that can be related with aging and protective factors that can lead to new therapeutic strategies.

\section{Authors' details}

${ }^{1}$ IBMC and ICBAS, UnIGENe, 4150-180, Porto, Portugal. ${ }^{2}$ Centro Hospitalar do Porto, Unidade Corino de Andrade, 4050 - 345, Porto, Portugal.

${ }^{1}$ IBMC and ICBAS, UnIGENe, 4150-180, Porto, Portugal

Full list of author information is available at the end of the article 
doi:10.1186/1750-1172-10-S1-03

Cite this article as: Lemos et al: Unravelling the epidemiology of lateonset and asymptomatic carriers of FAP ATTR V30M in a Portuguese population. Orphanet Journal of Rare Diseases 2015 10(Suppl 1):O3.

Submit your next manuscript to BioMed Central and take full advantage of:

- Convenient online submission

- Thorough peer review

- No space constraints or color figure charges

- Immediate publication on acceptance

- Inclusion in PubMed, CAS, Scopus and Google Scholar

- Research which is freely available for redistribution 